\title{
Aproximações com o chão da escola na vivência dos pibidianos de Educação Física
}

\author{
Approaches to the school floor in the experience of Physical Education pibidians \\ Aproximaciones al suelo escolar en la experiencia de los pibidianos de la Educación Física
}

Recebido: 11/03/2021 | Revisado: 17/03/2021 | Aceito: 22/03/2021 | Publicado: 29/03/2021

\author{
Monique Carvalho Ramalho \\ ORCID: https://orcid.org/0000-0002-6173-8733 \\ Universidade Estadual de Maringá, Brasil \\ E-mail: monicramalho@hotmail.com \\ Yedda Maria da Silva Caraçato \\ ORCID: https://orcid.org/0000-0002-6602-3921 \\ Universidade Estadual de Maringá, Brasil \\ E-mail: yeddacaracato@hotmail.com \\ Leonardo Cordeiro de Queiroz \\ ORCID: https://orcid.org/0000-0003-1608-3499 \\ Universidade Estadual de Maringá, Brasil \\ E-mail: leonnardoq@gmail.com \\ Francielli Ferreira da Rocha Romero \\ ORCID: https://orcid.org/0000-0001-7866-6070 \\ Universidade Estadual de Maringá, Brasil \\ E-mail: franciellirocha13@gmail.com \\ Bruna Solera \\ ORCID: https://orcid.org/0000-0001-5125-456X \\ Universidade Estadual de Maringá, Brasil \\ E-mail: brunasoleraef@gmail.com \\ Ana Luiza Barbosa Anversa \\ ORCID: https://orcid.org/0000-0003-4363-3433 \\ Universidade Estadual de Maringá, Brasil \\ E-mail: ana.beah@gmail.com \\ Patric Paludett Flores \\ ORCID: https://orcid.org/0000-0003-4865-7661 \\ Universidade Estadual de Maringá, Brasil \\ E-mail: patricpflores@gmail.com \\ Amauri Aparecido Bassoli de Oliveira \\ ORCID: https://orcid.org/0000-0002-2566-1476 \\ Universidade Estadual de Maringá, Brasil \\ E-mail: amauribassoli@gmail.com \\ Vânia de Fátima Matias de Souza \\ ORCID: https://orcid.org/0000-0003-4631-1245 \\ Universidade Estadual de Maringá, Brasil \\ E-mail:vfmatias@gmail.com
}

\begin{abstract}
Resumo
O objetivo do estudo foi investigar a representação do PIBID na formação inicial de professores de Educação Física. Participaram da pesquisa dez pibidianos, por meio do grupo focal. A interpretação das informações seguiu os encaminhamentos da análise de conteúdo. A partir dos resultados emergiram-se cinco categorias de análise: 1) O ingresso e a permanência no programa, 2) Conhecimentos sobre os objetivos do PIBID, 3) A universidade e o cotidiano escolar, 4) A aquisições de habilidades e competências docentes e 5) A influência do PIBID na Formação Inicial. Com base nos dados apresentados percebe-se a importância de uma formação teórico-prática, a necessidade de inserção dos pibidianos no cotidiano escolar, possibilitando experiências para a construção das competências para a prática pedagógica e propiciando conhecimentos da realidade escolar. Os resultados apontam que o PIBID representa uma elevação na qualidade da formação inicial.
\end{abstract}

Palavras-chave: Formação inicial; Formação docente; Programa de iniciação à docência.

\begin{abstract}
The objective of this study was to investigate the representation of PIBID in the initial training of Physical Education teachers. Ten pibidians participated in the study, through the focus group. The interpretation of the information followed the guidelines of the content analysis. Five categories of analysis emerged from the results: 1) Admission to and permanence in the program, 2) Knowledge about the objectives of PIBID, 3) The university and daily school life, 4) The acquisition of teaching skills and competences and 5) The influence of PIBID on initial training. Based on the data presented, the importance of a theoretical-practical training is perceived, as well as the need for the insertion of the
\end{abstract}


pibidians in daily school life, enabling experiences for the construction of competences for pedagogical practice and providing knowledge of the school reality. The results show that the PIBID represents an increase in the quality of initial training.

Keywords: Initial formation; Teacher training; Teaching initiation program.

\section{Resumen}

El objetivo del estudio fue investigar la representación de PIBID en la formación inicial de profesores de Educación Física. Diez pibidianos participaron en la investigación, a través del grupo focal. La interpretación de la información siguió las pautas del análisis de contenido. De los resultados surgieron cinco categorías de análisis: 1) Ingreso y permanencia en el programa, 2) Conocimiento sobre los objetivos del PIBID, 3) La vida universitaria y escolar, 4) La adquisición de habilidades y competencias docentes y 5) La influencia de PIBID en formación inicial. A partir de los datos presentados se percibe la importancia de la formación teórico-práctica, la necesidad de inserción de los pibidianos en la rutina escolar, posibilitando experiencias para la construcción de competencias para la práctica pedagógica y aportando conocimiento de la realidad escolar. Los resultados muestran que PIBID representa un aumento en la calidad de la formación inicial.

Palabras clave: Formación inicial; Educación del profesorado; Programa de iniciación docente.

\section{Introdução}

A educação na contemporaneidade está sustentada na matriz ideológica da formação integral do homem para o convívio em sociedade. Para tanto, o ambiente escolar constitui-se como um agente fundamental na ação constituinte desse sujeito, possibilitando o acesso aos conhecimentos historicamente produzidos alicerçado nas relações culturais, políticas e econômicas que reverberam sobre as práticas sociais, viabilizando-o a compreender a estruturada desta sociedade, dando-lhe condições para que este torne-se um sujeito crítico, reflexivo e com autonomia para transpor os saberes e conhecimentos para além dos muros da escola.

Nesse entendimento, o trabalho docente se configura como processo essencial à sociedade tanto dentro quanto fora dos muros da escola, ou seja, o professor traz consigo saberes e conhecimentos que são provenientes da escolarização e do universo social. A formação de professores é um processo contínuo, resultante de conhecimentos culturais ou de mundo e os científicos, no entanto, nem sempre essa linearidade ocorre, haja vista que no decorrer da história tem-se analisado os processos formativos nos quais algumas lacunas foram identificadas como necessárias a serem modificadas.

De acordo com Veiga (2009) a formação de professores pode ser entendida por duas perspectivas: sendo a primeira o professor enquanto tecnólogo do ensino que procura adequar esse processo de formação as demandas do mercado, ou seja, se baseia no saber fazer e, a segunda, enquanto agente social que tem uma formação que entenda a complexidade do trabalho docente.

Para além deste fato, vale destacar que a formação de professores é dividida em níveis inicial e continuada, a partir desses níveis Silva (2012, p.15) coloca que “O período de formação inicial, que é o primeiro momento de qualificação de uma determinada profissão, é importante, pois nele se adquirem conhecimentos essenciais à atuação profissional." Os cursos de formação inicial, teoricamente, devem preparar o futuro docente para a constituição da identidade profissional, promover o primeiro contato com a educação básica enquanto professor, a busca pelos saberes científicos, didáticos, culturais.

Pimenta (1999, p. 17-18) afirma que "para além da finalidade de conferir uma habilitação legal ao exercício profisssional da docência, do curso de formação inicial se espera que forme o professor ou que colabore para a sua formação.” Dessa forma, um problema encontrado na formação inicial é o distanciamento entre a instituição formadora e a educação básica, tendo em vista que é preciso formar professores que tenham conhecimentos específicos de sua área, entretanto é necessário aprender as habilidades, valores, atitudes e saberes necessários para a prática pedagógica.

Formar professores implica compreender a importância do papel da docência, propiciando uma profundidade cientificopedagógico que os capacite a enfrentar questões fundamentais da escola como instituição social, uma prática social que pressupõe as ideias de formação, reflexão e critica. (Veiga, 2009, p. 25) 
A partir da Lei de Diretrizes e Bases da Educação Nacional LDBN lei no 9.394/96 (Brasil, 1996) a Educação Física oficializa-se enquanto componente curricular obrigatório, enaltecendo a relevância acerca das reflexões sobre a Formação Inicial de professores nos cursos de Educação Física.

Nesse viés formativo, os estudos indicam mudanças essenciais na estrutura de aproximação entre universidade e escola durante este processo, segundo Flores (2018, p.16) os Estágios Curriculares Supervisionados e as Práticas como Componente Curricular do curso, são considerados “[...] eixos centrais dos currículos de formação na busca por aproximações com a realidade da escola, pois possibilitam vivências docentes ao longo do processo formativo [...]”.

O currículo do curso de Educação Física - licenciatura de uma universidade do noroeste do Paraná, a qual é o nosso lócus de pesquisa, garante o estágio nos anos finais do curso, o que dificulta o processo de formação de professores, uma vez que na teoria vão ser proporcionados os conhecimentos teóricos e esses vão ser colocados em prática no final do curso, fragmentando esse processo de formação. Desse modo a presente pesquisa se justifica pela necessidade de compreender o distanciamento entre os espaços de formação, tendo em vista que pode ocasionar uma formação fragmentada em teoria e prática, com base nesse fator, analisar a formação inicial do licenciando inserido no Programa Institucional de Bolsas de Iniciação à Docência (PIBID) edital 2018.

A partir disso há que se pensar como não fragmentar esse processo, sendo que o PIBID foi uma proposta da Coordenação de Aperfeiçoamento de Pessoal de Nível Superior (CAPES) a partir do Decreto n 6755/2009 que instituiu a Política Nacional de Formação de Profissionais do Magistério da Educação Básica, foi definido no Art. 10.

A CAPES incentivará a formação de profissionais do magistério para atuar na educação básica, mediante fomento a programas de iniciação à docência e concessão de bolsas a estudantes matriculados em cursos de licenciatura de graduação plena nas instituições de educação superior. (Brasil, 2009).

O PIBID é um programa que disponibiliza bolsas para acadêmicos de cursos de licenciatura visando proporcionar uma aproximação prática com as escolas na primeira metade da graduação, o programa é desenvolvido por instituições de educação superior (IES) em parcerias com as redes de educação básica. Os objetivos estabelecidos pela CAPES para o programa são: I. Incentivar a formação de docentes em nível superior para a educação básica; II. Contribuir para a valorização do magistério; III. Elevar a qualidade da formação inicial de professores nos cursos de licenciatura, promovendo a integração entre educação superior e educação básica; IV. Inserir os licenciandos no cotidiano de escolas da rede pública de educação, proporcionandolhes oportunidades de criação e participação em experiências metodológicas, tecnológicas e práticas docentes de caráter inovador e interdisciplinar que busquem a superação de problemas identificados no processo de ensino-aprendizagem; V. Incentivar escolas públicas de educação básica, mobilizando seus professores como coformadores dos futuros docentes e tornando-as protagonistas nos processos de formação inicial para o magistério; VI. Contribuir para a articulação entre teoria e prática necessárias à formação dos docentes, elevando a qualidade das ações acadêmicas nos cursos de licenciatura. (Brasil, 2018).

$\mathrm{Na}$ universidade pesquisada o programa se iniciou a partir do Edital 2009 proposto pela CAPES, levando em consideração que cada edital tem estabelecido critérios e regras diferentes, é determinado um tempo de vigência. Atualmente está em vigor o Edital 2018 com uma duração de 18 meses e com 256 pibidianos inseridos no programa. O curso de Educação Física, iniciou com um subprojeto em 2013 e está com um subprojeto no edital 2018 e possui 20 pibidianos incluídos.

O PIBID proporciona o contato inicial do licenciando com o ambiente escolar, ocorrendo na primeira metade da graduação e possibilitando a observação da prática didático-pedagógica dos professores que atuam no cotidiano das escolas públicas de educação básica.

Segundo Flores \& Krug (2011, s/n) "ao escolhermos ser professor, muitas são as certezas que devemos estar cientes, e uma delas é o fato de que estaremos em formação constante e que nosso desenvolvimento profissional vai se dando 
diariamente." Complementando com Silva (2010) formação profissional é influenciada pelo modo em que agimos e pensamos nas diferentes fases da vida. A partir do objetivo de investigar a representação do PIBID na formação inicial pelo olhar dos pibidianos, buscamos responder a seguinte questão problema: Qual a representatividade do PIBID para a formação profissional do futuro professor de Educação Física?

\section{Metodologia}

De acordo com Gil (2008), o presente estudo de cunho qualitativo e sob uma perspectiva descritiva se enquadra como pesquisa de campo, que permite observar de modo direto, as atividades do grupo estudado. A pesquisa tem como fonte central para a obtenção dos dados o uso de grupos focais, que se segundo Gatti (2005) permite entender o processo de construção da realidade por determinados grupos sociais, compreender práticas cotidianas, ações e reações a fatos e eventos, esse modo de coleta de dado proporciona a possibilidade de discussões informais de um grupo pequeno de pessoas que tenham vivência com o tema a ser discutido visando obter informações das atividades desenvolvidas e suas percepções sobre o assunto em questão. Desse modo a amostra foi composta por dez estudantes bolsistas de Educação Física licenciatura e foram nomeados como P1 a P10, tendo como critério de inclusão ser bolsistas do PIBID Edital 2018 e como critério de exclusão a não disponibilidade de horário em comum com os outros participantes,

“[...] Cada grupo focal não pode ser grande, mas também não pode ser excessivamente pequeno, ficando sua dimensão preferencialmente entre seis a 12 pessoas. Em geral, para projetos de pesquisa, o ideal é não trabalhar com mais de dez participantes. Grupos maiores limitam a participação, as oportunidades de trocas de idéias e elaborações, o aprofundamento no tratamento do tema e também os registros." (Gatti, 2005, p.22)

Para a realização do grupo focal todos os participantes assinaram o Termo de Consentimento Livre e Esclarecido (TCLE) e foram seguidos os procedimentos indicados por Gatti (2005) como: definir um local onde favoreça a interação entre os integrantes; ter um ou dois relatores para ajudar o moderador durante o grupo; A gravação por áudio para registrar; Oferecer informações para que os participantes fiquem a vontade, explicar os objetivos; Falar sobre o funcionamento do grupo focal, entre outras.

Para além da análise documental onde foram analisados as resoluções, decretos, editais relacionados pelo PIBID e a formação inicial de professores, foi realizado uma análise de conteúdo e foram elencadas categorias que se define como uma forma de classificar elementos ou aspectos que se relacionam, ou seja, trabalhar com categorias, significa agrupar expressões em torno de um conceito, (Gomes, 2001). A partir da coleta de dados, as categorias centrais da pesquisa foram: 1) O ingresso e a permanência no programa, 2) Conhecimentos sobre os objetivos do PIBID, 3) A universidade e o cotidiano escolar, 4) A aquisições de habilidades e competências docentes e 5) A influência do PIBID na Formação Inicial.

\section{Resultados e Discussão}

\subsection{O ingresso e a permanência no PIBID}

A partir da análise de dados, entendemos que todos os pibidianos se interessaram em participar do programa pela bolsa oferecida. Por meio das falas dos alunos, entende-se que a permanência no PIBID se deu pelas inúmeras experiências que são adquiridas e o conhecer da realidade escolar. P1 destaca que: "Sendo realista a princípio, a bolsa, mas o que manteve aqui foi as experiências na escola, essa iniciação à docência". "Para mim foi a bolsa também e depois para conhecer como é a realidade escolar, quanto mais antes fazer isso é melhor para a formação" (P3).

De acordo com Raush e Frantz (2013) com o processo de formação os participantes são inseridos no cotidiano escolar planejam e participam de experiências metodológicas e o atuar nas escolas e interagem com situações escolares reais. 
As novas experiências dentro do ambiente escolar é um fator muito importante para a permanência no programa, o PIBID possibilita a constituição da identidade profissional, o que nos leva de encontro aos relatos dos pibidianos, que a partir do momento em que está inserido no ambiente escolar logo no início do curso, tem a possibilidade de descobrir se a profissão docente é algo que se almeja em seu futuro.

Bom primeiro se você faz o pibid desde o primeiro ano da faculdade, você já vai saber se é aquilo que você quer, se você chegasse lá no penúltimo ano de faculdade nos estágios e vê que não é aquilo, mas você não vai largar o curso, você já fez quase tudo, ai você termina, vamos supor que você vai dar aula na escola e não é aquilo, vai formar um profissional ruim ou desinteressado para aquela profissão, entendeu, se alguém faz o Pibid desde o começo e resolve continuar naquele curso é porque já teve a experiência, sabe daquilo, então a tendência é formar um bom profissional mais interessado pela área o que é bom é melhor. (P1)

Por meio da promulgação da Resolução CFE n 03 em jun/87 o Conselho Federal de Educação definiu no Art. $1^{0}$ “A Formação dos Profissionais de Educação Física será feita em curso de graduação que conferirá o título de Bacharel e/ou Licenciado em Educação Física". Desse modo ao analisar as falas dos pibidianos entendemos que o PIBID influência na formação profissional, pois esse contato com o ambiente escolar no início do curso, facilita a escolha entre bacharel e licenciatura, como observamos nas falas de (P6) "queria ter uma experiência na escola, para saber se é isso que eu vou querer fazer na minha profissão, por que a gente ainda tem a opção de ir para o bacharel, estou testando" e (P10) "A gente ainda tem a opção de mudar pro bacharel caso a gente não queira assumir o papel de professor na sala de aula, caso a gente não queira continuar com essa vivência."

Acho que o PIBID é uma ótima escolha para pessoa saber se é a licenciatura que ela quer, acho que por eu ter entrado logo no primeiro ano fez muita diferença, e eu acho que eu indicaria para qualquer pessoa que queira conhecer esse lado. (P4)

Durante a profissão docente são encontrados muitos obstáculos, com o a desvalorização financeira, falta de reconhecimento do trabalho, falta de materiais, entre outros. Nas palavras de Darido (1995) a atuação profissional é complexa e a autora destacas alguns elementos que a compõem: as experiências anteriores do sujeito; as expectativas da comunidade escolar; as restrições do contexto de trabalho; O impacto da mídia nas expectativas dos alunos e dos próprios professores.

Baseando-se em que ser professor não é algo fácil, o programa segundo os pibidianos proporciona a vivência da prática pedagógica. (P4) "O PIBID faz você querer ser um bom professor, porque você vê algumas coisas e pensa eu não queria ser daquele jeito, eu acho que não é assim que se explica um jogo cooperativo, por exemplo.”

O PIBID ajuda a pensar que tipo de professor eu vou ser, como eu vou lidar no futuro com minhas turmas, vai até me ajudar para eu ver se é isso realmente que eu quero, antes mesmo de chegar na metade do curso, para não chegar e ver no estágio que não é, e desistir na metade do curso. (P2)

A partir dessa vivência é possível compreender os fatores que compõem a profissão docente proporcionando o entendimento de suas complexidades, dessa maneira facilita o processo de escolha da profissão a qual eles pretendem seguir.

\subsection{Conhecimentos sobre os objetivos do PIBID}

De acordo com a CAPES, o PIBID apresenta seis objetivos, quando questionado para os pibidianos sobre seus conhecimentos a respeito dos objetivos, é evidente que o entendimento que possuem é de maneira mais abrangente, o que nos 
leva a compreender que eles ingressam no PIBID e não sabem tudo o que programa pretende alcançar. Como é possível observar na fala de (P3) "Acho que de forma geral o PIBID assim é mais para promover essa experiência do primeiro momento."

Pra mim o objetivo do programa é dar uma iniciação à docência, a gente ter já um conhecimento de como que é "ta" do lado do ser um professor, acho que isso é o objetivo do pibid e melhorar nossa formação inicial, nossa experiência, como é ser professor. (P1)

Também acho que é proporcionar essa experiência pra gente, sendo uma forma de iniciação na escola pra gente ter uma base para aprimorar quando a gente "tornar" de fato efetivo na escola. (P4)

Observa-se na fala dos participantes, a inexistência de uma curiosidade para pesquisar mais sobre o PIBID e entender como o programa vai contribuir de forma efetiva em sua formação inicial, como vai proporcionar experiências dentro do cotidiano escolar, oportunizar o contato entre a educação básica e a educação superior elevando a qualidade da formação docente, o programa propicia a vivência da prática docente e também articulando a teoria e a prática.

As contribuições do PIBID vão além da formação inicial, ele também fornece subsidio para formação continuadas dos professores da educação básica, sendo possível uma troca de experiências e conhecimentos entre os participantes, os professores supervisores se tornam coformadores dos futuros docentes, complementando com as palavras de Santos (2016, p.9) "favoreceu o exercício da prática da reflexão, promoveu a aproximação maior entre alunos [...] e os pares [...] e o aperfeiçoamento da prática pedagógica, considerando suas concepções, perspectivas, funções e aprendizagens vividas no âmbito do programa.”

Ao analisar as informações da coleta podemos perceber que há um entendimento que os supervisores podem ajudar nesse processo de formação inicial, como se observa na fala de P2 "na iniciação à docência, no caso o PIBID, você já tem uma base do que você pode enfrentar no futuro e tem até a ajuda dos professores de como enfrentar".

Entretanto os pibidianos relatam também a falta de autonomia, liberdade e uma interação maior com os supervisores, como observa-se nas falas de (P8) "eu acho que na organização como um todo, não temos liberdade." e (P10) "os alunos mesmo falam, ah! são só estagiários."

Eu particularmente acho que é a impotência de não poder fazer nada em sala, você até tenta organizar de uma maneira e o professor que é titular vai lá e desfaz tudo que você fez, ai você se sente bem péssimo, daí perde mais o respeito que você não tem. (P6)

Sexta-feira eu e o P7 estávamos na sala e a professora teve que sair para ir na pedagogia e nisso a sala estava fazendo várias coisas erradas, mas como a gente não tem autoridade, a gente deixa passar, porque o que a gente vai fazer para controlar. (P2)

Acho que falta uma interação melhor entre a gente e os professores, só a gente que vem discutir o Pibid aqui, teve só uma reunião só que os professores vieram, falta essa interação, isso aqui é muito importante, e os professores não participam com gente, falte ter uma interação melhor entre a gente. (P1)

Para os pibidianos, os objetivos do programa podem ser alcançados e por meio desse elemento ocorre uma melhora na formação inicial, mas ressalvam em suas falas que poderia ser melhor, que a vivência deveria ser em mais de uma realidade escolar. "O que o P1 falou é bem real, que todo mundo pudesse trabalhar em mais escolas, porque por exemplo eu e a P5 a gente estava no colégio e foi para o outro e foi uma diferença absurda de ambientes." (P4)

Melhora nossa formação, muito mais do que se a gente não fizesse o PIBID, não teria essa melhora sem o PIBID, acho que poderia ser melhor ainda se tivesse um experiência em alguma outra escola, mas ficaria muito difícil fazer isso, por exemplo vivenciar escolas diferentes, tem um pessoal que faz no colégio militar, a gente faz na pública, é duas unidades diferente, se tivesse mais experiências e em escolas diferentes, acrescentaria ainda mais para formação inicial. (P1) 
A partir do que se foi exposto nesta categoria, entendemos que os conhecimentos sobre os objetivos do PIBID são gerais, entretanto percebe-se que de forma indireta em suas falas que os objetivos podem ser alcançados, pois a partir dos relatos se evidencia que a qualidade da formação inicial é elevada e que ocorrendo essa inserção dos pibidianos no cotidiano escolar contribui com a articulação da teoria e prática.

\subsection{Universidade e o cotidiano escolar}

O distanciamento entre o cotidiano escolar e as IES é evidente e um dos objetivos do PIBID é fazer com que ocorra uma aproximação. Devido a esse distanciamento ocorre a fragmentação em teoria e prática dos cursos de licenciatura. No currículo do curso de Educação Física - Licenciatura nesta universidade é proporcionado para os acadêmicos as vivências práticas nos anos finais, durante o Estágio Curricular Supervisionado (ECS), em contrapartida os pibidianos tem essa vivência da aplicação da teoria na prática logo no início de sua formação.

O estágio é muito pouco e muita gente depois que sair daqui só vai ter a experiência dentro do estágio, vai sair daqui já para trabalhar e vai acabar desistindo, porque não teve uma oportunidade maior, de estar dentro da escola, de vivenciar aquilo que a gente consegue vivenciar no PIBID. (P7)

Porque no caso o estágio é apenas seis meses em tal lugar e seis em outro, aqui no pibid a gente tem um ano em cada turma, acompanhando o professor, que de certo modo vai ajudar a gente com alguns problemas que podem surgir durante sobre nosso futuro profissional. (P2)

Silva e Timóteo (2013) apontam que as vivências ocorridas durante o PIBID e o estágio são diferentes, durante os estágios, têm contato apenas com a experiência da docência, ou seja, o aluno da licenciatura vai à escola, mas todas as suas atenções estão voltadas apenas para a observação da sala de aula na qual irá realizar a regência, PIBID por sua vez, possibilita ao bolsista permanecer mais tempo na escola, podendo vivenciar não só a sala de aula como também outras atividades como planejamento pedagógico.

De acordo com Koepsel et al. (2018, p.61) entende-se que o PIBID proporciona a "possibilidade de rever o percurso formativo e, a partir da organização dos trabalhos na escola e na Universidade, reduzir essa polaridade histórica entre teoria e prática ao exigir uma imersão maior do futuro professor no contexto escolar [...]”. Nesse sentindo, os pibidianos entendem que o programa possibilita essa associação entre a teoria e prática, como destacamos na fala de (P6) "acho que o PIBID é sair um pouco da teoria e ir prática. [...] É saber pegar essas teorias, várias teorias e aplicar na aula para aquela serie no momento.”

Porque os professores relatam como se fosse lindo, bonito e que tudo vai funcionar lá no colégio, e qualquer coisa vai dar, e quando você se depara com isso na realidade da escola, a maioria das coisas que você planeja dá errado, você tem que repensar no que você vai fazer, não dá para pegar tudo o professor vai passar, você não vai conseguir passar tudo aquilo. (P1)

Com base na análise das respostas, a teoria dos conhecimentos das práticas corporais colocada durante a formação inicial não corresponde com o que é encontrado na escola, evidencia-se um distanciamento entre a realidade escolar, falta um entendimento de que às vezes não é possível fazer daquela maneira que é colocada, na maioria das vezes por falta de estrutura, falta de materiais, entre outros obstáculos. Reforçando a ideia que o PIBID proporciona a compreensão da realidade escolar, fazendo com os pibidianos saibam como é realmente o dia-a-dia da profissão docente, como se observa na fala de (P4) "igual trabalhar ginástica artística, tem que trabalhar e tal, está lá no negócio, tem que trabalhar, mas vai pegar uma turma com 40 alunos para fazer." 
Eu acho que talvez a educação física para pessoas com deficiência, a matéria "lá", você tem que inserir todos na mesma atividade, mas ai um surdo, o outro é cego, o outro não anda e o outro "não sei o que", todos estudam juntos e tem um que tem autismo, mas você tem que incluir, "tá" mais ai você fala: posso dividir em dois grupos? não, isso vai causar exclusão, "tá" mais ai não vou atrapalhar ou causar mal desenvolvimento de um ou de outro, não, mas e lá na hora, tem que fazer e acabou, então essa é a teoria que a gente tem e lá na hora não dá para aplicar. (P6)

Segundo Reis (2019, p.44) o PIBID pode "proporcionar aos licenciandos a antecipação de sua relação, durante sua formação, com as situações de trabalho, consideradas tão formativas quanto aquelas ações desenvolvidas no interior dos cursos de graduação."

Apoiando-se nas respostas dos pibidianos, o programa possibilita uma melhor compreensão do cotidiano escolar, de como funciona a escola no dia-a-dia e em suas falas nota-se que há uma diferença no ambiente escolar que vamos encontrar após a formação inicial colocado pela universidade e o real que você encontra na escola, e a ação de propiciar essa experiência prepara o licenciando para os entraves encontrados na profissão docente.

\subsection{A aquisições de habilidades e competências docentes}

A partir do que o programa pretende alcançar em relação a integração entre a educação superior e a educação básica, procuramos entender se com o PIBID possibilitando esse contato com o cotidiano escolar desde o início de sua formação inicial, é possível que os pibidianos tenham uma maior vivência com as habilidades e competências necessárias para a prática docente, as quais serão consolidadas no decorrer da profissão docente. Como destaca, Farias e Nascimento (2012, p.71) "torna-se relevante explicitar que, durante a formação inicial, deveriam ser absorvidos os saberes e as competências para que o professor venha a estabelecer uma relação harmoniosa com sua profissão.”

Perrenoud (1999, p.7) define competência "como sendo uma capacidade de agir eficazmente em um determinado tipo de situação, apoiada em conhecimentos, mas sem limitar-se a eles". Batista et al. (2012) colocam que a definição de competência é complexa e envolve muitas perspectivas e que a competência requer experiência e reflexão, podemos então colocar o PIBID como uma forma de ampliação dessa experiência, podendo contribuir para a aquisição de competências e habilidades para a docência. Em sua pesquisa, Nascimento (1998, p.84) destacas vários autores e suas definições para competência, dentre elas, "ela está relacionada com o desenvolvimento do próprio indivíduo e da sua formação pessoal. Envolve questões relativas ao desenvolvimento de auto-conceito, personalidade e caráter."

Perrenoud (2000) traz um referencial de competências para o ofício de professor, as quais são em dez grandes famílias, destacamos entre elas as competências de organizar e dirigir situações de aprendizagem; conceber e fazer evoluir os dispositivos de diferenciação e trabalhar em equipe, mas ressalva que as competências não são atitudes e sim mobilização que orquestra os recursos. Além disso cada uma dessas "10 grandes famílias" tem suas competências específicas.

Nesse sentido, as respostas dos pibidianos indicam que é construídas algumas das competências específicas de organizar e dirigir as situações de aprendizagem, pois com o contato com inúmeras turmas com personalidades e desenvolvimento diferentes proporciona a "capacidade de reconstruir um planejamento didático a partir dos alunos" Perrenoud (2000, p.26), ou seja, saber que aquela atividade planejada ela pode dar certo ou não para aquela turma ou aluno e saber direcionar a aula para que os alunos assimilem aquele conteúdo.

Tem o lance de turma também, que a P5 já falou, a gente sabe que um plano de aula para três $8^{\circ}$ anos pode dar certo em uma, mas que nas três salas diferentes não vai dar certo, pelo menos eu e a P5, a gente tenta fazer uma divisão de atividades que a gente sabe que vai dar certo em um $8^{\circ}$, que vai dar certo em outro $8^{\circ}$, mas com a mesma proposta é claro e que vai incluir e atividade dá certo, porque se não acontece. (P4)

Não só a personalidade, também o nível de aprendizagem, a gente tem essa consciência que nem toda turma vai ser igual, precisamos de adaptação, tanto pela personalidade tanto pelo nível de aprendizagem, porque não adianta chegar 
numa turma que relativamente é dez e querer avançar o conteúdo igual como numa turma que não é dez. [...] A gente tem essa consciência que nem toda turma vai ser igual. (P5)

Outra competência que começa a ser construída nesse processo de formação, é conceber e fazer evoluir os dispositivos de diferenciação, pois os pibidianos entendem que é necessário o auxílio de ajuda externa para proporcionar uma aula que desenvolva os alunos com deficiência.

"Um grupo reunido em torno de um projeto em comum, cuja realização passa por diversas formas de acordo e de cooperação" (Perrenoud, 2000, p.83). Nesta direção com a análise das respostas é possível compreender que os pibidianos entende que um planejamento em conjunto com os professores supervisores poderia contribuir para além do que o PIBID já contribui, o ato de realizar o plano de aula e em conjunto com o supervisor e a partir disso analisar, corrigir e definir se está de acordo com a realidade escolar, pois caso não estiver é necessário adaptar, e dessa forma aprender e construir essa competência.

Desse modo destacamos a fala de (P5) "Mas eu acho que falta o planejamento em conjunto, montar junto, a gente ter um horário, uma hora atividade para gente conseguir planejar junto com o professor, por que acaba que a gente planeja."

A gente tem que elaborar mais e mais vezes o plano de aula, então a gente erra, erra e depois acerta, quando você faz o plano de aula, pensa o plano de aula, você vai compreendendo, você já assimilando o que dá certo, o que dá para fazer e o que não dá. [...] "ai" eu passo pro professor supervisor, ele olha, vê o que vai dar certo, tira dúvida comigo, vê se vai mudar alguma coisa, se não precisar e mantém aquilo, pelo menos comigo é assim. (P1)

Como destaca Nascimento (1998, p. 87):

"Apesar de não existir um consenso geral sobre a definição operacional de competência profissional em Educação Física
e Desportos, pode ser aceitável defini-la como um conjunto de conhecimentos, habilidades e atitudes necessárias para
uma atuação profissional adequada. Esta caracterização indica que o profissional necessita possuir conhecimentos
amplos da realidade na qual vive em diferentes dimensões (cultural, social, econômica), bem como conhecimentos
específicos dos conteúdos necessários para o seu desempenho profissional. Da mesma forma, necessita dominar
habilidades que o capacitem para o desenvolvimento de propostas pedagógicas. Além disso, precisa assumir e
comprometer-se com atitudes de respeito (tolerância, flexibilidade, reflexão) e de aceitação da diversidade de gênero,
raça, idioma e religião."

Em seu estudo o autor determina dois grupos de competências da educação física e do desporto, Dimensão dos Conhecimentos (Conceitual, Procedimental e Contextual) e Dimensão das Habilidades. O primeiro grupo, o da dimensão do conhecimento, o componente conceitual, onde as competências podem ser determinadas como ter domínio de conhecimentos dos conteúdos do ensino em Educação Fisica, efeitos, indicações, contraindicações das atividades físicas. Sobre o domínio de conhecimentos de Pedagogia, sobre a iniciação desportiva, o papel da Educação Fisica no contexto escolar e extra-escolar constituem as competências da componente procedimental. A dimensão do conhecimento contextual é o terceiro grupo, onde as competências são definidas como "o conhecimento de características especificas da estrutura e funcionamento do sistema educativo e desportivo, bem como das oportunidades, expectativas e constrangimentos existentes no contexto escolar e extraescolar." (Nascimento, 1998, p.99). O último grupo é a dimensão da Habilidades, e o autor destaca:

“[...] as competências que apresentaram maior importância atribuída versaram sobre as componentes de construção e projeção de situações futuras (ser capaz de planejar ou construir programas para a pratica de atividades físicas para diferentes clientelas), relacional ou comunicacional nas interações sociais (ser capaz de transmitir os conteúdos de forma clara e concisa), observacional (ser capaz de avaliar os desempenhos e caracterizar os contextos e os sujeitos), motivacional ou incentivadora a ação (ser capaz de despertar o gosto para a prática de atividades físicas), interventora (ser capaz de racionalizar e gerir pessoas, espaços, tempo e materiais) e de investigação continua da própria atuação (ser capaz de auto-avaliar a respectiva atuação profissional).” (Nascimento, 1998, p.107). 
Desse modo, entendemos que os pibidianos começaram a construção das competências fundamentas pelo autor.

Ao questionarmos os pibidianos se na percepção deles o PIBID proporciona a aquisição de habilidades e competências necessárias para a docente, observa-se pelas suas falas que sim.

Sim, no começo é muito difícil você estar na frente do pessoal, para falar, para dar uma aula, é muito difícil, você fica muito nervoso, ai conforme você vai fazendo isso mais e mais vezes, você vai acostumando, vai ficando tranquilo dar uma aula, para falar em frente, essas coisas, por exemplo falar com um público grande é a principal competência que professor tem que ter, então o pibid ajuda nisso. (P1)

Por que da gente aqui algumas tem matéria de educação física escola e a gente sabe que a nossa participação na aula é bem mais presente e a gente entende o que é trabalhado, porque a gente já tem essa experiência. [...] Mas tem diferença de quem faz pibid e quem não faz, até para montar aula, a gente meio que já sabe os problemas que pode acontecer e de repente uma pessoa que não faz pibid não conta com aquilo. (P4)

No estudo de Marcon; Nascimento e Graça (2007), eles concluíram que

"Enquanto principais elementos constituintes da prática como componente curricular, que mais contribuem para o desenvolvimento das competências pedagógicas dos estudantes-professores, destacou-se a realização do planejamento das aulas, a possibilidade de aproximação do contexto escolar, o acompanhamento do professor-formador, as reflexões e os debates sobre a prática pedagógica, a inserção lenta e gradativa no mundo da docência, como preparação para os Estágios Supervisionados, e a descoberta da vocação para ser professor."

De modo que vai ao encontro as falas destacadas, os pibidianos realizam o planejamento das aulas, ocorre a aproximação com a escola antes dos anos finais, tem a possibilidade de refletir e debater com os professores supervisores da educação básica e os professores do ensino superior e são inserido no ambiente escolar de forma gradativa, primeiro observando as aulas, depois participando e por fim ministrando as aulas, dessa forma é possibilitado o desenvolvimentos das competências e habilidades docentes.

A partir da análise das respostas entendemos que o programa contribui para a construção de habilidades e competências para a atuação docente, entretanto entendemos que as competências não são adquiridas e sim construídas no decorrer da formação de professores.

\subsection{A influência do PIBID na formação inicial}

Nesta última categoria, buscamos entender a influência do PIBID na Formação inicial dos professores de educação física, sendo ela de forma negativa ou positiva e de acordo com as respostas dos pibidianos, eles não assimilam nenhum ponto negativo para o programa. Como destaca o participante P1 "não vejo o PIBID atrapalhando na minha formação, pelo contrário".

Acho que torna a gente mais chato, querer as coisas melhores sabe, se o pega o plano de um colega seu e fala "mano" você já pensou em aplicar isso aqui, isso não vai dar certo nunca, talvez mais crítico, mas é uma coisa boa né. (P6)

Dessa maneira entendemos que o PIBID pode influenciar na formação profissional dos futuros professores de Educação física de forma positiva, por meio da experiência prática os pibidianos pode entender se a profissão docente é algo que ele deseja realizar para o "resto da sua vida". Na questão do entender o cotidiano escolar, influência na reflexão dos conteúdos que são abordados durante a graduação, e pensar no como vai ser trabalhar aquele conteúdo na realidade escola.

Não sei se acontece com vocês mas geralmente eu venho meio automático para aula, passa no quadro, eu anoto e estudo para prova, próximo, minha nota está boa e pronto, passei a olhar para aula e lembrar para que eu estou aprendendo aquilo, nossa "aquilo ali" é porque tem uma criança na escola que é assim, e eu acredito que vai por conta da postura 
dos professores daqui, chega aqui e joga uma teoria e fala aprende que vai ter prova. Mas eu vou usar isso "aquilo lá" na escola como, que é o meu trabalho todo dia. (P6)

Você consegue filtrar na aula teórica o que você vai usar realmente na prática ou não, você consegue estabelecer que nunca vou fazer isso na escola ou então você pensa vou usar, dá para fazer. (P1)

O que nos leva ao encontro com as palavras de Lima et al (2018) que conclui que o PIBID influenciou positivamente na formação inicial dos participantes de sua pesquisa e com o estudo de Braibante \& Wollmann (2012, p.171) o PIBID "influenciou de maneira significativa no futuro profissional dos acadêmicos [...]". Desse modo podemos concluir que o programa influência de forma positiva na formação inicial de professores com as experiências que o PIBID proporciona aos seus integrantes.

\section{Conclusão}

As análises descritas nas falas dos participantes evidenciaram o PIBID como uma ação essencial para a formação docente principalmente para o nível inicial, uma vez que os relatos evidenciaram o fato de que as experiências que o programa proporciona aos futuros professores, é um meio para melhorar a qualidade desse processo. Os relatos indicam ainda que a inserção dos pibidianos no cotidiano escolar possibilitou momentos na formação que buscam otimizar e potencializar relação da práxis pedagógica efetiva entre os campos da teoria e da prática.

Destacou-se ainda nos relatos que a experiência em vivenciar essa inserção no ambiente escolar, apenas nos anos finais da formação inicial, como é oportunizado para os estudantes que não estão vinculados com o PIBID, pode resultar numa formação fragmentada, ou seja, são encontradas dificuldades em associar a teoria com a prática. Outro fator que destacamos nesse estudo é sobre a oportunidade que os pibidianos possuem de vivenciar a prática docente nos anos iniciais e podendo auxiliar na constituição da identidade profissional.

Evidenciou-se por meio das análises dos relatos que as relações com o cotidiano escolar que o PIBID proporciona aos pibidianos são de grande importância para a compreensão da realidade encontrada nas escolas e a partir disso construir as competências para o trabalho docente. Concluímos que o PIBID representa uma influência de forma positiva na formação profissional professores de Educação Física, contribuindo para a construção das competências e habilidades para a atuação docente, propicia o contato dos pibidianos com o cotidiano escolar e dessa maneira oportuniza uma formação teórico-prática, melhorando a qualidade da formação inicial de professores.

\section{Referências}

Batista, P. M. F.; Pereira, A. L., \& Graça, A. B. S. (2012). A (re)configuração da identidade profissional no espaço formativo do estágio profissional. In: Farias, GO e Nascimento, JV. (Org.). Construção da identidade profissional em Educação Física: da formação a ação. Florianópolis: Editora da UDESC.

Braibante, M. E. F., \& Wollmann, E. M. (2012). A Influência do PIBID na Formação dos Acadêmicos de Química. Revista Química nova na escola, 34(4).

Brasil. MEC/CAPES/FNDE. EDITAL No 07/2018. Programa Institucional de Bolsa de Iniciação à Docência. Brasília.

Brasil. Lei 9394/1996. Estabelece as Diretrizes e Bases da Educação Nacional. Diário Oficial da União, 1996.

Brasil. Conselho Federal De Educação. Resolução $n^{\circ}$ 03, de 16 de junho de 1987. Fixa os mínimos de conteúdo e duração a serem observados nos cursos de graduação em Educação Física (Bacharelado e/ou Licenciatura Plena). Publicado no DOU de 10.09.1987.

Brasil. Decreto $n^{\circ}$ 6.755, de 29 de janeiro de 2009. Institui a Política Nacional de Formação de Profissionais do Magistério da Educação Básica, disciplina a atuação da Coordenação de Aperfeiçoamento de Pessoal de Nível Superior -CAPES no fomento a programas de formação inicial e continuada, e dá outras providências. Diário Oficial da União, Brasília.

Darido, S. C. (1995). Teoria, prática e reflexão na formação profissional em Educação Física. V Simpósio Paulista de Educação Física, Revista Motriz, 1(12).

Farias, G. O., \& Nascimento, J. V. (2012). Construção da identidade profissional: metamorfose na carreira docente em educação física. In: Farias, G. O.; Nascimento, J. V. (Org.). Construção da identidade profissional em Educação Física: da formação a ação. Florianópolis: Editora da UDESC. 
Research, Society and Development, v. 10, n. 4, e2910413789, 2021

(CC BY 4.0) | ISSN 2525-3409 | DOI: http://dx.doi.org/10.33448/rsd-v10i4.13789

Flores, P. P. (2018). O processo de identização docente durante o Estágio Curricular Supervisionado: em jogo no campo da Educação Física. 2018. 212f. Tese (Doutorado em Educação Física) - Centro de Ciências da Saúde. Universidade Estadual de Maringá, Maringá.

Flores, P. P., \& Krug, H. N. (2011). Compreendendo o desenvolvimento profissional docente: reflexões sobre a (trans)formação de professores de educação física.P@rtes, 4(12).

Gatti, B. A. (2008). Grupo focal na pesquisa em ciências sociais e humanas. Liber Livro.

Gil, A. C. (2002). Como elaborar projetos de pesquisa, (4a ed.), Editora Atlas.

Gomes, R. (2001). A análise de dados em pesquisa qualitativa. In: Minayo, M. C. de S. (org.). Pesquisa social: teoria, método e criatividade. (33a ed.), Vozes.

Koepsel, E. C. N.; Arrais, L. F. L., \& Sforni, M. S. F. (2018). PIBID e formação docente: desafios da unidade teoria e prática. In: Martins, J. Á., \& Zappone, M. H. Y. (Org.). Formação Docente: percursos e reflexões a partir do PIBID-UEM. (21a ed.), EDUEM.

Lima, N. C. F. (2018). Formação docente dos bolsistas do PIBID de educação física: estudo de caso da Universidade de Gurupi (UnirG). Cadernos UniFOA, 38 .

Nascimento, J. V. (1998). A formação universitária em educação física e desportos: uma abordagem sobre o ambiente percebido e a auto-percepção de competência profissional de formandos brasileiros e portugueses. 1998. 380f. Tese (Doutorado em Ciências do Desporto) Faculdade de Ciências do Desporto e de Educação Física, Universidade do Porto, Porto.

Pimenta, S. G. (1999). Formação de professores: identidade e saberes da docência. In: Pimenta, SG. (Org.). Saberes pedagógicos e atividade docente. Cortez.

Perrenoud, P. (2000). 10 novas competências para ensinar. ArtMed.

Perrenoud, P. (1999). Construir as competências desde a escola. Artmed.

Rausch, R. B., \& Frantz, M. J. (2013). Contribuições do PIBID à formação inicial de professores na compreensão de licenciandos bolsistas. Revista Atos de Pesquisa em Educação, 8.

Reis, E. J. B. (2012). O PIBID e seus desdobramentos para a formação inicial de professores de Educação Física. 2019. 145 f. Dissertação (Doutorado em Educação Física) - Centro de Ciências da Saúde. Universidade Estadual de Maringá, Maringá.

Santos, M. A. B. (2016). Experiência formativa do professor supervisor: estudo de caso do PIBID/Educação Física/UECE. 2016. 167 f. Dissertação (Mestrado em Educação), Universidade Estadual do Ceará, Centro de Educação, Fortaleza, Ceará.

Silva, S. L. P. O. (2019). O Estágio Supervisionado na formação inicial de licenciados em Educação Física no Paraná. 2012. 153 f. Dissertação (Mestrado em Educação Física) - Centro de Ciências da Saúde. Universidade Estadual de Maringá, Maringá.

Silva, C. A., Temoteo, A. S. S. G. (2013). O pibid e a formação docente: um estudo sobre as nuances dessa relação. In: V Fiped - Fórum Internacional De Pedagogia, Vitória da Conquista - BA. Pesquisa na graduação: justiça social, diversidade e emancipação humana, v.1.

Veiga, I. P. A. (2009). A aventura de formar professores. Papirus. 